\title{
Biochemical analysis of patients with mutations in MTHFD1 and a diagnosis of methylenetetrahydrofolate dehydrogenase 1 deficiency
}

Bidla, Gawa ; Watkins, David ; Chéry, Céline ; Froese, D. Sean ; Ells, Courtney ; Kerachian, Matin ; Saskin, Avi ; Christensen, Karen E ; Gilfix, Brian M ; Guéant, Jean-Louis ; Rosenblatt, David S

\begin{abstract}
MTHFD1 is a trifunctional protein containing 10-formyltetrahydrofolate synthetase, 5,10methenyltetrahydrofolate cyclohydrolase and 5,10-methylenetetrahydrofolate dehydrogenase activities. It is encoded by MTHFD1 and functions in the cytoplasmic folate cycle where it is involved in de novo purine synthesis, synthesis of thymidylate and remethylation of homocysteine to methionine. Since the first reported case of severe combined immunodeficiency resulting from MTHFD1 mutations, seven additional patients ascertained through molecular analysis have been reported with variable phenotypes, including megaloblastic anemia, atypical hemolytic uremic syndrome, hyperhomocysteinemia, microangiopathy, infections and autoimmune diseases. We determined the level of MTHFD1 expression and dehydrogenase specific activity in cell extracts from cultured fibroblasts of three previously reported patients, as well as a patient with megaloblastic anemia and recurrent infections with compound heterozygous MTHFD1 variants that were predicted to be deleterious. MTHFD1 protein expression determined by Western blotting in fibroblast extracts from three of the patients was markedly decreased compared to expression in wild type cells (between 4.8 and $14.3 \%$ of mean control values). MTHFD1 expression in the fourth patient was approximately $44 \%$ of mean control values. There was no detectable methylenetetrahydrofolate dehydrogenase specific activity in extracts from any of the four patients. This is the first measurement of MTHFD1 function in MTHFD1 deficient patients and confirms the previous molecular diagnoses.
\end{abstract}

DOI: https://doi.org/10.1016/j.ymgme.2020.04.008

Posted at the Zurich Open Repository and Archive, University of Zurich

ZORA URL: https://doi.org/10.5167/uzh-193442

Journal Article

Accepted Version

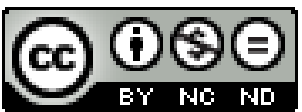

The following work is licensed under a Creative Commons: Attribution-NonCommercial-NoDerivatives 4.0 International (CC BY-NC-ND 4.0) License.

Originally published at:

Bidla, Gawa; Watkins, David; Chéry, Céline; Froese, D. Sean; Ells, Courtney; Kerachian, Matin; Saskin, Avi; Christensen, Karen E; Gilfix, Brian M; Guéant, Jean-Louis; Rosenblatt, David S (2020). Biochemical analysis of patients with mutations in MTHFD1 and a diagnosis of methylenetetrahydrofolate dehydrogenase 1 deficiency. Molecular Genetics and Metabolism, 130(3):179-182.

DOI: https://doi.org/10.1016/j.ymgme.2020.04.008 
Molecular Genetics and Metabolism

\section{Biochemical Analysis of Patients with Mutations in MTHFD1 and a Diagnosis of Methylenetetrahydrofolate Dehydrogenase 1 Deficiency \\ --Manuscript Draft--}

\begin{tabular}{|c|c|}
\hline Manuscript Number: & MGM-D-20-00033R1 \\
\hline Article Type: & Research Paper \\
\hline Keywords: & $\begin{array}{l}\text { MTHFD1; SCID; Megaloblastic anemia; Hyperhomocysteinemia, One-carbon } \\
\text { metabolism; Folate }\end{array}$ \\
\hline Corresponding Author: & $\begin{array}{l}\text { David Watkins } \\
\text { McGill University } \\
\text { Montreal, PQ Canada }\end{array}$ \\
\hline First Author: & David Watkins \\
\hline \multirow[t]{11}{*}{ Order of Authors: } & David Watkins \\
\hline & Gawa Bidla, M.D., Ph.D. \\
\hline & Céline Chéry \\
\hline & D. Sean Froese, Ph.D. \\
\hline & Courtney Ells, M.Sc. \\
\hline & Matin Kerachian \\
\hline & Avi Saskin, M.D. \\
\hline & Karen E. Christensen, Ph.D. \\
\hline & Brian M. Gilfix, M.D., Ph.D. \\
\hline & Jean-Louis Guéant, M.D. \\
\hline & David S. Rosenblatt, M.D. \\
\hline Abstract: & $\begin{array}{l}\text { MTHFD1 is a trifunctional protein containing } 10 \text {-formyltetrahydrofolate synthetase, } \\
5,10 \text {-methenyltetrahydrofolate cyclohydrolase and } 5,10 \text {-methylenetetrahydrofolate } \\
\text { dehydrogenase activities. It is encoded by MTHFD1 and functions in the cytoplasmic } \\
\text { folate cycle where it is involved in de novo purine synthesis, synthesis of thymidylate } \\
\text { and remethylation of homocysteine to methionine. Since the first reported case of } \\
\text { severe combined immunodeficiency resulting from MTHFD1 mutations, seven } \\
\text { additional patients ascertained through molecular analysis have been reported with } \\
\text { variable phenotypes, including megaloblastic anemia, atypical hemolytic uremic } \\
\text { syndrome, hyperhomocysteinemia, microangiopathy, infections and autoimmune } \\
\text { diseases. We determined the level of MTHFD1 expression and dehydrogenase } \\
\text { specific activity in cell extracts from cultured fibroblasts of three previously reported } \\
\text { patients, as well as a patient with megaloblastic anemia and recurrent infections with } \\
\text { compound heterozygous MTHFD1 variants that were predicted to be deleterious. } \\
\text { MTHFD1 protein expression determined by Western blotting in fibroblast extracts from } \\
\text { three of the patients was markedly decreased compared to expression in wild type } \\
\text { cells (between } 4.8 \text { and } 14.3 \text { percent of mean control values). MTHFD1 expression in } \\
\text { the fourth patient was approximately } 44 \% \text { of mean control values. There was no } \\
\text { detectable methylenetetrahydrofolate dehydrogenase specific activity in extracts from } \\
\text { any of the four patients. This is the first measurement of MTHFD1 function in MTHFD1 } \\
\text { deficient patients and confirms the previous molecular diagnoses. }\end{array}$ \\
\hline \multirow[t]{2}{*}{ Response to Reviewers: } & $\begin{array}{l}\text { Re: Manuscript Number: MGM-D-20-00033 } \\
\text { Biochemical Analysis of Patients with Mutations in MTHFD1 and a Diagnosis of } \\
\text { Methylenetetrahydrofolate Dehydrogenase } 1 \text { Deficiency }\end{array}$ \\
\hline & Dear Dr. McCabe, \\
\hline
\end{tabular}


We are submitting a revised version of the above manuscript addressing the issues raised by the reviewers.

Reviewer 1:

1. The authors describe MTHFD1 protein levels as being relative to the "control." But was the loading control (B-actin) also factored into this calculation? There seem to be significant differences in total protein loads in Figure 1. Please describe the western blot quantification in more detail or justify the decision not to control for total protein using $B$ actin.

We have modified section 2.3 of 'Materials and Methods' to clarify how MTHFD1 expression was determined: "MTHFD1 expression was normalized to $\beta$-actin expression in the same lane of the gel, to compensate for differences in protein loading in different lanes. Patient MTHFD1 values were expressed as a percentage of control MTHFD1 expression on the same blot."

2. The antibody described to detect MTHFD1 is from reference 19. The antibody described in this reference seems to have been generated from full length MOUSE MTHFD1. However, the proteins probed for are HUMAN MTHFD1. Was this antibody validated against human MTHFD1? Was the antibody generated against a peptide or a protein? Antibodies generated against a peptide or part of the MTHFD1 protein might not bind the "mutated" MTHFD1 from patient cells. Please clarify.

We have added a fuller description of the anti-MTHFD1 antibody that was used in our studies: "The MTHFD1 antibody was generated using purified preparations of the entire intact mouse MTHFD1 protein, which is $93.2 \%$ identical $/ 97 \%$ homologous to human MTHFD1, so it should not cause the type of artifacts described by the reviewer. This antibody has been used previously to detect the human protein in mthfd1-/- cells transfected with human MTHFD1 cDNA (unpublished data)."

3. Very minor comment: I understand the mutation is referenced in text, but describing the "*" as a stop codon or early truncation in the legend of Table1 would keep the reader from having to search for a second reference.

Over the past several years an asterisk has become the preferred symbol for a stop codon in mutation nomenclature, and we believe that in this context the use of an asterisk in Table 1 is unambiguous.

Reviewer 2: There are no specific issues to address in this reviewer's comments.

We hope that with these revisions our manuscript will be acceptable for publication in Molecular Genetics and Metabolism.

Sincerely,

David Watkins PhD 
Dear Dr. McCabe,

Re: Manuscript Number MGM-D-20-00033

We are resubmitting a revised version of the above manuscript. Attached is the revised version of the manuscript as well as a response to the points raised by the reviewers. We hope that the revised version will be acceptable for publication in Molecular Genetics and Metabolism.

\section{Sincerely}

David Watkins PhD 
Re: Manuscript Number: MGM-D-20-00033

Biochemical Analysis of Patients with Mutations in MTHFD1 and a Diagnosis of Methylenetetrahydrofolate Dehydrogenase 1 Deficiency

Dear Dr. McCabe,

We are submitting a revised version of the above manuscript addressing the issues raised by the reviewers.

Reviewer 1:

1. The authors describe MTHFD1 protein levels as being relative to the "control." But was the loading control (B-actin) also factored into this calculation? There seem to be significant differences in total protein loads in Figure 1. Please describe the western blot quantification in more detail or justify the decision not to control for total protein using $B$ actin.

We have modified section 2.3 of 'Materials and Methods' to clarify how MTHFD1 expression was determined: "MTHFD1 expression was normalized to $\beta$-actin expression in the same lane of the gel, to compensate for differences in protein loading in different lanes. Patient MTHFD1 values were expressed as a percentage of control MTHFD1 expression on the same blot."

2. The antibody described to detect MTHFD1 is from reference 19. The antibody described in this reference seems to have been generated from full length MOUSE MTHFD1. However, the proteins probed for are HUMAN MTHFD1. Was this antibody validated against human MTHFD1? Was the antibody generated against a peptide or a protein? Antibodies generated against a peptide or part of the MTHFD1 protein might not bind the "mutated" MTHFD1 from patient cells. Please clarify.

We have added a fuller description of the anti-MTHFD1 antibody that was used in our studies: "The MTHFD1 antibody was generated using purified preparations of the entire intact mouse MTHFD1 protein, which is $93.2 \%$ identical/97\% homologous to human MTHFD1, so it should not cause the type of artifacts described by the reviewer. This antibody has been used previously to detect the human protein in $m t h f d 1-/-$ cells transfected with human MTHFDI cDNA (unpublished data)."

3. Very minor comment: I understand the mutation is -referenced in text, but describing the "*" as a stop codon or early truncation in the legend of Table1 would keep the reader from having to search for a second reference.

Over the past several years an asterisk has become the preferred symbol for a stop codon in mutation nomenclature, and we believe that in this context the use of an asterisk in Table 1 is unambiguous.

Reviewer 2: There are no specific issues to address in this reviewer's comments.

We hope that with these revisions our manuscript will be acceptable for publication in Molecular Genetics and Metabolism.

Sincerely, 
David Watkins PhD 


\section{Biochemical Analysis of Patients with Mutations in MTHFD1 and a Diagnosis of Methylenetetrahydrofolate Dehydrogenase 1 Deficiency}

Gawa Bidla ${ }^{a}$, David Watkins ${ }^{a b c}$, Céline Chéry ${ }^{d}$, D. Sean Froese ${ }^{e}$, Courtney Ells ${ }^{a}$, Matin Karachian ${ }^{\mathrm{a}}$, Avi Saskin ${ }^{\mathrm{b}}$, Karen E. Christensen ${ }^{\mathrm{ac}}$, Brian M. Gilfix ${ }^{\mathrm{cf}}$, Jean-Louis Guéant $^{d}$, David S. Rosenblattabcf

a Department of Human Genetics, McGill University, Montreal, Quebec, Canada

b Division of Medical Genetics, Department of Specialized Medicine, McGill University Health Centre, Montreal, Quebec, Canada

c. Research Institute of the McGill University Health Centre, Montreal, Quebec, Canada

d Inserm-U954, National reference centre for inherited metabolic diseases, University Hospital Centre, Nancy, France

e Division of Metabolism and Children's Research Center, University Children's Hospital, Steinwiesstrasse 75, CH-8032 Zürich, Switzerland

f Division of Medical Biochemistry, Department of Specialized Medicine, McGill University Health Centre, Montreal, Quebec, Canada

Corresponding Author:

David Watkins

Research Institute of the McGill University Health Centre Child Health and Human Development 2001 Decarie Blvd, Room E01-2389 
Montreal QC H4A 3J1

david.watkins@mcgill.ca

Tel: 514-934-1934 extension 42973 
Abstract

MTHFD1 is a trifunctional protein containing 10-formyltetrahydrofolate synthetase, 5,10-methenyltetrahydrofolate cyclohydrolase and 5,10-methylenetetrahydrofolate dehydrogenase activities. It is encoded by MTHFD1 and functions in the cytoplasmic folate cycle where it is involved in de novo purine synthesis, synthesis of thymidylate and remethylation of homocysteine to methionine. Since the first reported case of severe combined immunodeficiency resulting from MTHFD1 mutations, seven additional patients ascertained through molecular analysis have been reported with variable phenotypes, including megaloblastic anemia, atypical hemolytic uremic syndrome, hyperhomocysteinemia, microangiopathy, infections and autoimmune diseases. We determined the level of MTHFD1 expression and dehydrogenase specific activity in cell extracts from cultured fibroblasts of three previously reported patients, as well as a patient with megaloblastic anemia and recurrent infections with compound heterozygous MTHFD1 variants that were predicted to be deleterious. MTHFD1 protein expression determined by Western blotting in fibroblast extracts from three of the patients was markedly decreased compared to expression in wild type cells (between 4.8 and 14.3 percent of mean control values). MTHFD1 expression in the fourth patient was approximately $44 \%$ of mean control values. There was no detectable methylenetetrahydrofolate dehydrogenase specific activity in extracts from any of the four patients. This is the first measurement of MTHFD1 function in MTHFD1 deficient patients and confirms the previous molecular diagnoses. 


\section{Keywords}

MTHFD1; SCID; Megaloblastic anemia; Hyperhomocysteinemia, One-carbon metabolism; Folate

\section{Abbreviations}

BSA - bovine serum albumin

MeCbl - methylcobalamin

PBS - phosphate buffered saline

TBST - Tris buffered saline with Tween-20

TCA - trichloroacetic acid

SCID - severe combined immune deficiency 


\section{Introduction}

MTHFD1 (MIM 172460) encodes a protein that contains three distinct enzyme activities: 10-formyltetrahydrofolate synthetase (EC 6.3.4.3), 5,10-methenyltetrahydrofolate cyclohydrolase (EC 3.5.4.9) and 5,10-methylenetetrahydrofolate dehydrogenase (EC 1.5.1.5). These activities catalyze three sequential reactions in cytoplasmic one-carbon metabolism that generate derivatives of tetrahydrofolate used as one-carbon sources in biosynthetic processes occurring in the cytoplasm [1,2] including de novo purine synthesis, thymidylate synthesis, and remethylation of homocysteine to methionine. MTHFD1 has also been shown to translocate to the nucleus during S-phase [3] as well as during folate or MTHFD1 deficiency [4], suggesting a critical role of MTHFD1 for de novo nuclear thymidylate synthesis and a mechanism by which MTHFD1 deficiency can lead to megaloblastic anemia [4]. Two major domains confer the trifunctional enzymatic activity of MTHFD1: an amino-terminal domain containing the dehydrogenase and cyclohydrolase activities, and a larger C-terminal synthetase domain [5]. MTHFD1 clearly plays an essential role in cellular function as homozygous knockout mutations in Mthfd1 are embryonic lethal in mice [6,7].

Since the first reported case of severe combined immunodeficiency (SCID) associated with variants in MTHFD1 [8,9], seven additional patients have been reported [10-12]. All patients had compound heterozygous variants in MTHFD1 except one with a homozygous variant identified in a population-based newborn screen for SCID in Saudi Arabia [12]. In addition to variable phenotypes of SCID, clinical manifestations of 
MTHFD1 deficiency include megaloblastic anemia (common to all MTHFD1 deficiency patients reported thus far), atypical hemolytic uremic syndrome, anisocytosis, autoimmune diseases and microangiopathy. The highly variable clinical phenotypes caused by pathogenic MTHFD1 variants may be the result of variable degrees of residual function of its constituent activities.

All reported cases of MTHFD1 deficiency have been diagnosed by the identification of likely causal variants by exome or targeted sequencing. Biochemical characterization of cultured fibroblasts derived from three patients showed decreased synthesis of methionine from labeled formate and mildly reduced levels of methylcobalamin (MeCbl) $[8,10]$. These findings likely reflect decreased provision of 5-methyltetrahdrofolate, necessary for MeCbl synthesis, due to decreased MTHFD1 function. Direct assay of MTHFD1 enzyme activities in patient fibroblasts has not been reported. We have measured methylenetetrahydrofolate dehydrogenase protein levels and specific activity in human fibroblast extracts and have demonstrated that these are deficient in patients with a diagnosis of MTHFD1 deficiency based on gene sequencing.

2. Materials and methods

2.1 Patients 
Clinical and molecular findings in Patient $1[8,9]$ as well as Patients 2 and $3[10]$ have been previously reported. Patients 1 to 3 are numbered as in the publication of Burda et al [10]. The clinical history of Patient 4 has also been previously been reported although the MTHFD1 variants were detected later by exome sequencing [13]. She is a 34-yearold woman with megaloblastic anemia at 6 months of life, related to cobalamin deficiency caused by a heterozygous GIF variant coupled with a heterozygous FUT2 variant [13]. The anemia responded to therapy with cobalamin in the absence of folate treatment. She has a history of immunodeficiency from infancy with recurrent lung infections that responded partially to treatment with immunoglobulin. She also had milk intolerance. Since the immunodeficiency did not fit the diagnosis of cobalamin deficiency, she underwent exome sequencing which identified compound heterozygous variants in MTHFD1. The MTHFD1 variants identified in the four patients are summarized in Table 1.

The first variant in Patient 4, NM_005956.4:c.146C>T (p.Ser49Phe) is listed as likely pathogenic in ClinVar (ClinVar ID: 446306) [14] and affects a highly conserved residue in the NADP-binding site of the dehydrogenase/cyclohydrolase catalytic site. It has previously been shown to segregate with disease in trans with a known pathogenic variant, NM_005956.4:c.673G>T (p.Glu225Ter) (ClinVar ID: 446307) in multiple affected individuals [10,15], and in silico prediction tools consistently consider this variant as deleterious (PolyPhen2, SIFT, GERP, and CADD scores), which has been confirmed experimentally [10]. The second variant, NM_005956.4:c.826G>C (p.Gly276Arg) has not been previously reported. It is a rare variant not present in the 
population database gnomAD, a repository of sequencing data from over 140,000 seemingly healthy adults [16], and other sequencing data repositories. It affects a highly conserved residue in the dehydrogenase catalytic site [17] and in silico prediction tools consistently consider this variant as deleterious (PolyPhen2, SIFT, GERP, and CADD scores). Segregation analysis revealed both variants to segregate with disease in her affected brother. Moreover, these variants are in trans with her sibling having the identical genotype, while her mother was found to be heterozygous for this novel variant. Her father was unavailable for testing.

\subsection{Cell Culture}

Patient-derived and control fibroblasts were maintained at $37^{\circ} \mathrm{C}$ and $5 \% \mathrm{CO}_{2}$ in modified Eagle's minimum essential medium with non-essential amino acids supplemented with $5 \%$ fetal bovine serum and $5 \%$ iron-enriched bovine calf serum (Wisent Bio Products).

\subsection{Western Blotting}

Confluent fibroblasts in $175 \mathrm{~cm}^{2}$ tissue culture flasks were washed with phosphate buffered saline (PBS), trypsinized, pelleted and stored at $-80^{\circ} \mathrm{C}$ until used. Pellets were suspended in RIPA lysis buffer (PBS containing 1\% IGEPAL CA-630 (Sigma-Aldrich), $0.5 \%$ sodium deoxycholate and $0.1 \%$ SDS) containing $1 \times$ Pierce Protease Inhibitor Mix (EDTA-free; Thermo Fisher Scientific), incubated on ice for 20 minutes and centrifuged

at $4^{\circ} \mathrm{C}$ for 15 minutes at $13,000 \times \mathrm{g}$. Supernatants where mixed with $4 \times$ Laemmli 
Sample Buffer (Bio-Rad Laboratories) and heated at $95^{\circ} \mathrm{C}$ for 5 minutes before storage at $-80^{\circ} \mathrm{C}$. Protein content of extracts was determined by the Lowry assay with bovine serum albumin (BSA) as a standard [18].

Twenty-five $\mu \mathrm{g}$ aliquots of cell extract from patient and control fibroblasts were loaded onto $10 \%$ SDS-polyacrylamide gels, run at 100 volts for 1.5 hours in Tris/glycine buffer $\mathrm{pH} 8.3(25 \mathrm{mmol} / \mathrm{L}$ Tris, $192 \mathrm{mmol} / \mathrm{L}$ glycine) containing $0.1 \% \mathrm{SDS}$, and transferred to nitrocellulose membrane for 1 hour at 100 volts in Tris/glycine buffer containing $10 \%$ methanol. The membrane was cut into two and incubated with $5 \%$ milk blocking solution for 1 hour. After washing with $1 x$ Tris buffered saline containing $0.05 \%$ Tween-20 (TBST), membrane halves were incubated overnight with either rabbit anti-MTHFD1 (1:2000 dilution, [19]) or anti- $\beta$-actin (1:5000 dilution, Cell Signaling Technology) antibodies. The MTHFD1 antibody was generated using purified preparations of the entire intact mouse MTHFD1 protein, which is $93.2 \%$ identical $/ 97 \%$ homologous to human MTHFD1. This antibody has been used previously to detect the human protein in Mthfd1-/- cells transfected with human MTHFD1 cDNA (unpublished data). The membranes were then washed with TBST, incubated with Goat-Anti-Rabbit IgG HRPconjugate (Bio-Rad Laboratories) visualized by chemiluminescence using Pierce ECL Western blotting substrate (ThermoFisher Scientific) following manufacturer's instructions, and documented with an Amersham Imager 600. Protein expression was quantified using Amersham Imager 600 Analysis Software version 1.0 (GE Healthcare Life Sciences). MTHFD1 expression was normalized to $\beta$-actin expression in the same lane of the gel, to compensate for differences in protein loading in different lanes. 
Patient MTHFD1 values were expressed as a percentage of control MTHFD1 expression on the same blot.

\subsection{Methylenetetrahydrofolate Dehydrogenase Assay}

Pelleted cells were resuspended in $300 \mu \mathrm{L}$ of extraction buffer $(0.1 \mathrm{~mol} / \mathrm{L}$ potassium phosphate $\mathrm{pH} 7.3 ; 0.04 x$ of Pierce Protease Inhibitor mix, EDTA-free; $35.3 \mathrm{mmol} / \mathrm{L} \beta$ mercaptoethanol) and sonicated on ice using a small long probe. Sonication comprised of five 10 -second pulses with one-minute pauses between pulses. A $0.24 x$ volume of glycerol was added and the mixture was centrifuged at 9,300 $\mathrm{g}$ for 10 minutes at room temperature. The supernatant was transferred to a fresh tube and stored at $-80^{\circ} \mathrm{C}$ until used. Protein content of the lysate was determined using a Lowry Assay with BSA as a standard [18].

Methylenetetrahydrofolate dehydrogenase activity was determined by measuring the optical density (OD) of the methenyltetrahydrofolate reaction product at $350 \mathrm{~nm}$ [20]. Assays were performed in triplicate for each cell line, with one blank. $250 \mu \mathrm{g}$ (20 to $35 \mu \mathrm{L}$ ) of cell extract was added at time 0 to a $500 \mu \mathrm{L}$ reaction mixture comprised of 0.1 $\mathrm{mmol} / \mathrm{L}$ potassium phosphate $\mathrm{pH} 7.3,0.144 \mathrm{~mol} / \mathrm{L} \beta$-mercaptoethanol, $0.2 \mathrm{mmol} / \mathrm{L}$ tetrahydrofolate trihydrochloride (Schirks Laboratories, Jona, Switzerland), $2.3 \mathrm{mmol} / \mathrm{L}$ formaldehyde, $0.17 \mathrm{mg} / \mathrm{mL} \mathrm{NADP}{ }^{+}$at $30^{\circ} \mathrm{C}$. The reaction was terminated after 30 minutes by adding an equal volume of $7 \%$ trichloroacetic acid (TCA). Blanks were prepared by adding the cell extract to the reaction mix after the TCA. 
Lactate dehydrogenase activity was measured on a Beckman AU5800 analyzer in the Central Laboratory of the McGill University Health Centre using the manufacturer's reagents.

3. Results:

\subsection{MTHFD1 Expression}

Western blotting demonstrated markedly reduced levels of MTHFD1 protein compared to controls in Patients 1 and 2; levels in Patient 3 were lower than in controls but somewhat higher than in the other patients (Figure 1). Quantification of MTHFD1 protein levels, expressed as a percentage of control values on the same blot, were $5.4 \%$ and 7.2\% (replicate experiments) for Patient 1, 4.8\% and 5.1\% for Patient 2, 13.9\% and $14.3 \%$ for Patient 3, and $46 \%$ and $41.6 \%$ for Patient 4 (Table 2). MTHFD1 expression in the mother of Patient 4 was similar to that in her daughter (38.8\% and $39.2 \%)$.

\subsection{Methylenetetrahydrofolate Dehydrogenase Activity}

Methylenetetrahydrofolate dehydrogenase activity was not detected in fibroblast extracts of patients 1, 2, 3 and 4 (Table 2). Extracts from the mother of patient 4 showed an intermediate level of dehydrogenase specific activity (38-54\% of wild type specific 
activity). Lactate dehydrogenase specific activity in equal volumes of fibroblast extracts was similar in both control and patient samples, between 9021 to $11833 \mathrm{U} / \mathrm{L}$.

\section{Discussion:}

MTHFD1 encodes a cytosolic trifunctional enzyme that catalyzes the condensation of mitochondria-derived formate with tetrahydrofolate to form 10-formyltetrahydrofolate (10-formyltetrahydrofolate synthetase activity), and its sequential conversion to 5,10 methenyltetrahydrofolate (5,10-methenyltetrahydrofolate cyclohydrolase) and 5,10methylenetetrahydrofolate (5,10-methylenetetrahydrofolate dehydrogenase), generating one-carbon units required for de novo purine biosynthesis, thymidylate synthesis and remethylation of homocysteine to form methionine [1,2]. In all reports of patients with MTHFD1 deficiency, diagnosis has been achieved by sequencing studies that identified presumably causal MTHFD1 variants in individuals with clinical findings consistent with the disorder (generally megaloblastic anemia and SCID). Somatic cell studies in Patients 1,2 and 3 have shown decreased incorporation of label from $\left[{ }^{14} \mathrm{C}\right]$ formate into methionine, and decreased synthesis of methylcobalamin from exogenous cyanocobalamin in fibroblasts $[8,10]$, reflecting reduced provision of its precursor 5,10 methylenetetrahydrofolate. In a study of fibroblasts from Patient 1, there was evidence of decreased thymidylate synthesis and homocysteine remethylation in the presence of 
normal purine biosynthesis, reflecting relative sparing of 10 -formyltetrahydrofolate synthetase activity in this individual [4]. However, specific activity of MTHFD1 has not been measured for any of the reported patients.

In the present study, we investigated expression of the MTHFD1 protein and measured the specific activity of its 5,10-methylentetrahydrofolate dehydrogenase component in fibroblasts from four MTHFD1 deficient patients (three previously reported patients and one new patient). We found variably decreased MTHFD1 protein levels and no detectable dehydrogenase activity. These results represent the first direct demonstration of decreased MTHFD1 function in patients with this disorder, and support the previous molecular diagnoses. In Patients 1 and 2, MTHFD1 expression was markedly reduced (5-7\% and $4-5 \%$ of control MTHFD1expression, respectively) as determined by Western blotting analysis. This in itself can explain the lack of dehydrogenase function in patient extracts. MTHFD1 expression was somewhat higher in Patient 3 (13-14\% of controls), who carried a nonsense variant in trans with a missense variant located in the $\mathrm{NADP}^{+}$binding site of the dehydrogenase active site [10]. MTHFD1 expression was also higher (41-46\% of controls) in Patient 4; both variants in this individual were predicted to affect the dehydrogenase/cyclohydrolase domain of the protein and not MTHFD1 expression. This suggests that the missense variants in Patients 3 and 4 resulted in expression of protein forms that retained no dehydrogenase activity.

In addition to the SCID phenotype, Patient 4 had megaloblastic anemia, which appears 
to be a hallmark of MTHFD1 deficiency. However, the anemia was primarily caused by the patient's cobalamin deficiency, which was related to decreased secretion and fucosylation of gastric intrinsic factor [13]. Although Patient 4 shares a heterozygous MTHFD1 variant with Patient 3 and her siblings, their phenotypes and degree of severity differ. This may be due in part to the differences in the residual amounts of the three MTHFD1 activities contributed by the other MTHFD1 allele in these individuals. Patient 4's brother carries the same compound heterozygous MTHFD1 mutations and shows similar immunological phenotypes to Patient 4. Consistent with our predictions, the mother of Patient 4 with no clinical manifestations of MTHFD1 deficiency is heterozygous for the novel NM_005956.4:c.826G>C (p.Gly276Arg) MTHFD1 variant and shows a dehydrogenase specific activity that is roughly half of wild type level.

The enzyme assay was effective at identifying a lack of methylenetetrahydrofolate dehydrogenase activity in each of the patients that we tested. Evaluation of patients with partial dehydrogenase activity will require experimental establishment of a reference range, as the mother of Patient 4 is heterozygous for the novel MTHFD1 variant, shows no clinical manifestations of MTHFD1 deficiency and has a dehydrogenase specific activity that is roughly half of wild type level.

As a first step to defining the relationship between enzyme activity and deleterious variants in MTHFD1, we have demonstrated that cells from patients with a number of different variants have a decrease in the quantity and activity of the enzyme. As new 
variants continue to be identified by genomics, these assays will be invaluable in their assessment and classification.

\section{Acknowledgments}

We wish to thank Camilah Arbabian-Urquilla for assistance with tissue culture. DSF is supported by the Swiss National Science Foundation, Grant number: 31003A_175779. This is a publication of the Hess B. and Diane Finestone Laboratory in memory of Jacob and Jenny Finestone. 
5. References:

1. Christensen KE, MacKenzie RE. Mitochondrial one-carbon metabolism is adapted to the specific needs of yeast, plants and mammals. BioEssays 28:595605,2006

2. Fox JT, Stover PJ. Folate-mediated one-carbon metabolism. Vitamins Hormones $79: 1-14,2011$

3. Field MS, Kamynina E, Agunloye OC, Liebenthal RP, Lamarre SG, Brosnan ME, Brosnan JT, Stover PJ. Nuclear enrichment of folate cofactors and methylenetetrahydrofolate dehydrogenase 1 (MTHFD1) protect de novo thymidylate biosynthesis during folate deficiency. J Biol Chem 289:29642-29650, 2014

4. Field MS, Kamynina E, Watkins D, Rosenblatt DS, Stover PJ. Human mutations in methylenetetrahydrofolate dehydrogenase 1 impair nuclear de novo thymidylate biosynthesis. Proc Natl Acad Sci USA 112:400-405, 2015

5. Hum W, MacKenzie RE. Expression of active domains of a human folatedependent trifunctional enzyme in Escherichia coli. Protein Engineering 4:493500

6. Christensen KE, Deng L, Leung KY, Arning E, Bottiglieri T, Malysheva OV, Caudill MA, Krupenko NI, Greene ND, Jerome-Majewska L, MacKenzie RE, Rozen R. A novel mouse model for genetic variation in 10-formyltetrahydrofolate synthetase exhibits disturbed purine synthesis with impacts on pregnancy and embryonic development. Hum Mol Genet 22:3705-3719 
7. MacFarlane AJ, Perry CA, Girnary HH, Gao D, Allen RH, Stabler SP, Shane B, Stover P. Mthfd1 is an essential gene in mice and alters biomarkers of impaired one-carbon metabolism. J Biol Chem 284:1533-1539, 2009

8. Watkins D, Schwartzentruber JA, Ganesh J, Orange JS, Kaplan BS, Dempsey Nunez L, Majewski J, Rosenblatt DS. Novel inborn error of folate metabolism: identification by exome capture and sequencing of mutations in the MTHFD1 gene in a single proband. J Med Genet 48:590-592, 2011

9. Keller MD, Ganesh J, Heltzer M, Paessler M, Bergqvist C, Baluarte HJ, Watkins D, Rosenblatt DS, Orange JS. Severe combined immunodeficiency resulting from mutations in MTHFD1. Pediatrics 131:e629-e634, 2013

10. Burda P, Kuster A, Hjalmarson O, Suormala T, Bürer C, Lutz S, Roussey G, Christa L, Asin-Cayuela J, Kollberg G, Andersson BA, Watkins D, Rosenblatt DS, Fowler B, Holme E, Froese DS, Baumgartner MR. Characterization and review of MTHFD1 deficiency: four new patients, cellular delineation and response to folic and folinic acid treatment. J Inher Metab Dis 38:863-872, 2015

11. Ramakrishnan KA, Pengelly RJ, Gao Y, Morgan M, Patel SV, Davies EG, Ennis S, Faust SN, Williams AP. Precision molecular diagnosis defines specific therapy in combined immunodeficiency with megaloblastic anemia secondary to MTHFD1 deficiency. J Allergy Clin Immunol Pract 4:1160-1166, 2016

12. Al-Mousa H, Al-Dakheel G, Jabr A, Elbadaoui F, Abouelhoda M, Baig M, Monies D, Meyer B, Hawwari A, Dasouki M. High incidence of severe combined immunodeficiency disease in Saudi Arabia detected through combined T cell 
receptor excision circle and next generation sequencing of newborn dried blood spots. Front Immunol 9:782, 2018

13. Chery C, Hehn A, Mrabet N, Oussaleh A, Jeannesson E, Besseau C, Alberto JM, Gross I, Josse T, Gérard P, Guéant-Rodriguez RM, Freund JN, Devignes J.; Bourgaud F, Peyrin-Biroulet L, Guéant JL. Gastric intrinsic factor deficiency with combined GIF heterozygous mutations and FUT2 secretor variant. Biochimie 95:995-1001, 2013

14. National Center for Biotechnology Information. ClinVar; [VCV000446306.1], https://www.ncbi.nlm.nih.gov/clinvar/variation/VCV000446306.1 (accessed Dec. 17, 2019).

15. National Center for Biotechnology Information. ClinVar; [VCV000446307.1], https://www.ncbi.nlm.nih.gov/clinvar/variation/VCV000446307.1 (accessed Dec. 17, 2019).

16. Karczewski KJ, Francioli L C, Tiao G, Cummings B.B, Alföldi J, Wang Q, Collins RL, Laricchia KM, Ganna A, Birnbaum DP, Gauthier LD, Brand H, Solomonson M, Watts NA, Rhodes D, Singer-Berk M, England EM, Seaby EG, Kosmicki JA, Walters RK, Tashman K, Farjoun Y, Banks E, Poterba T, Wang A, Seed C, Whiffen N, Chong .X, Samocha KE, Pierce-Hoffman E, Zappala Z, O'DonnellLuria AH, Minikil EV, Weisburd B, Lek M, Ware JS, Vital C, Armean IM, Bergelson L, Cibulskis K, Connolly KM, Covarrubias M, Donnelly S, Ferriera S, Gabriel S, Gentry J, Gupta N, Jeandet T, Kaplan D, Llanwarne C, Munshi R, Novod S, Petrillo N, Roazen D, Ruana-Rubio V, Saltzman A, Schleicher M, Soto J, Tibbetts K, Tolonen C, Wade G, Talkowski ME.; The Genome Aggregation 
Database Consortium Neale BM, Daly MJ, Gauthier LD. Variation across 141,456 human exomes and genomes reveals the spectrum of loss-of-function intolerance across human protein-coding genes. BioRxiv, 531210, 2019.

17. Christensen KE, Patel H, Kuzmanov U, Mejia NR, MacKenzie RE. Disruption of the Mthfd1 gene reveals a monofunctional 10-formyltetrahydrofolate synthetase in mammalian mitochondria. J Biol Chem 280:7597-7602, 2005

18. Lowry OH, Rosebrough NJ, Farr AL, Randall RJ. Protein measurement with the Folin phenol reagent. J Biol Chem 193:265-275, 1951

19. Gardam MA, Mejia NR, MacKenzie RE. The NADP-dependent trifunctional methylenetetrahydrofolate dehydrogenase purified from mouse liver is immunologically distinct from the mouse NAD-dependent bifunctional enzyme. Biochem Cell Biol 66:66-70, 1988

20. MacKenzie RE, Tan LUKL. Methylenetetrahydrofolate dehydrogenasemethenyltetrahydrofolate cyclohydrolase-formyltetrahydrofolate synthetase. A multifunctional protein from porcine liver. Methods Enzymol 66:609-615

21. Mejia NR, MacKenzie RE. NAD-dependent methylenetetrahydrofolate dehydrogenase is expressed by immortal cells. J Biol Chem 260:14616-14620, 1985 


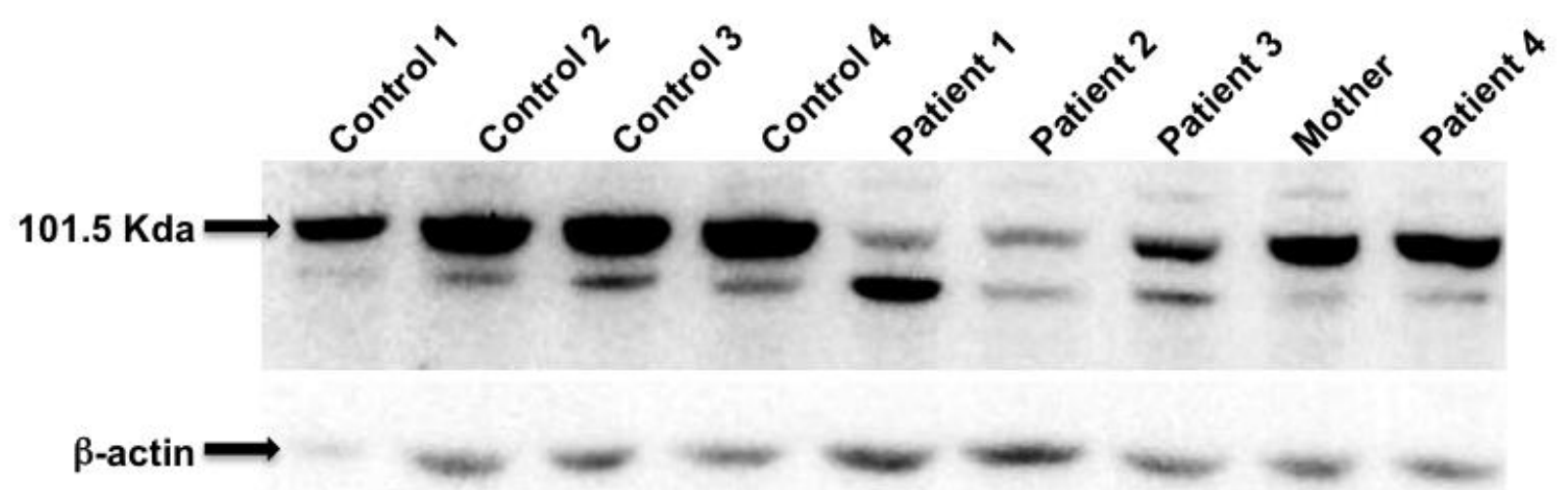

Figure 1: Western blot analysis of MTHFD1 expression

Ten percent SDS-PAGE of $25 \mu \mathrm{g}$ of cell extracts from four control fibroblast lines, and four MTHFD1 patients (Patient 1 to 4), as well as the mother (of Patient 4). Upper band (black arrow) represents MTHFD1. Quantification of bands is shown in Table 2 (Extract 1). $\beta$-actin loading control is shown below. 


\begin{tabular}{|c|c|c|c|}
\hline & Variants & Protein Change & Reference \\
\hline Patient 1 & $\begin{array}{l}\text { c. } 517 C>T \\
\text { c. } 727+1 G>A\end{array}$ & $\begin{array}{l}\text { p.R173C } \\
\text { Splice }\end{array}$ & 8 \\
\hline Patient 2 & $\begin{array}{l}\text { c.806C>T } \\
\text { c.1674G>A }\end{array}$ & $\begin{array}{l}\text { p.T269l } \\
\text { Skip exon }\end{array}$ & 10 \\
\hline Patient 3 & $\begin{array}{l}\text { c. } 146 C>T \\
c .673 G>T\end{array}$ & $\begin{array}{l}\text { p.S49F } \\
\text { p.E225* }\end{array}$ & 10 \\
\hline Patient 4 & $\begin{array}{l}\text { c. } 146 \mathrm{C}>\mathrm{T} \\
\mathrm{c} .826 \mathrm{G}>\mathrm{C}\end{array}$ & $\begin{array}{l}\text { p.S49F } \\
\text { p.G276R }\end{array}$ & This study \\
\hline
\end{tabular}

Table 1. MTHFD1 variants of patients in the current study 


\begin{tabular}{|c|c|c|c|c|}
\hline \multirow[t]{2}{*}{ Patient } & \multicolumn{2}{|c|}{$\begin{array}{l}\text { Protein Expression } \\
\% \text { Control Expression }\end{array}$} & \multicolumn{2}{|c|}{$\begin{array}{c}\text { MTHFD1 Dehydrogenase Specific Activity } \\
\text { (nmole/min/mg protein) }\end{array}$} \\
\hline & Extract 1 & Extract 2 & Extract 1 & Extract 2 \\
\hline Patient 1 & 5.4 & 7.2 & nd & nd \\
\hline Patient 2 & 4.8 & 5.1 & nd & nd \\
\hline Patient 3 & 13.9 & 14.3 & nd & nd \\
\hline Patient 4 & 46.0 & 41.6 & nd & nd \\
\hline $\begin{array}{l}\text { Mother, } \\
\text { Patient } 4\end{array}$ & 38.8 & 39.2 & 0.59 & 0.34 \\
\hline Control & 100 & 100 & 1.09 & 0.88 \\
\hline
\end{tabular}

Table 2: Protein expression and methylenetetrahydrofolate dehydrogenase specific activity in two independently extracted fibroblast extracts. MTHFD1 protein expression in patient fibroblast extracts is expressed as a percentage of MTHFD1 protein levels in control cells on the same blot. MTHFD1 dehydrogenase (nmole/min/mg) after 30 minutes incubation at $30^{\circ} \mathrm{C}$ in reported patients (Patient 1 to Patient 3 ), referred patient (Patient 4), mother of patient 4 and control wild type fibroblasts $(\mathrm{MCH} 23) . \mathrm{nd}=$ not detected. The range of specific activity of MTHFD1 dehydrogenase in six independently 
extracted and tested fibroblast extracts from a wild type control $(\mathrm{MCH} 23)$ was 0.83 to $1.35 \mathrm{nmole} / \mathrm{min} / \mathrm{mg}$ with a mean specific activity of $1.14 \mathrm{nmole} / \mathrm{min} / \mathrm{mg}$ and a standard deviation of 0.17 . All data points in MTHFD1 dehydrogenase specific activity are mean of triplicate experiments. Reported MTHFD1 dehydrogenase specific activity in wild type human fibroblasts is $1.25 \mathrm{nmole} / \mathrm{min} / \mathrm{mg}$ [21] 